\title{
Erratum to: Appearances of screen-detected versus symptomatic colorectal cancers at $\mathrm{CT}$ colonography
}

\author{
Andrew A. Plumb ${ }^{1}$. Fiona Pathiraja ${ }^{1} \cdot$ Claire Nickerson $^{2} \cdot$ Katherine Wooldrage $^{3}$. \\ David Burling ${ }^{4} \cdot$ Stuart A. Taylor ${ }^{1}$ • Wendy S. Atkin ${ }^{3} \cdot$ Steve Halligan $^{1}$
}

Published online: 17 May 2016

(C) European Society of Radiology 2016

Erratum to: Eur Radiol

DOI 10.1007/s00330-016-4293-7

Owing to an oversight in typesetting, Fig. 2 was duplicated and Fig. 3 (below) omitted from the original publication. The mistake has since been corrected. The publisher apologises for this error and the inconvenience caused.

The online version of the original article can be found at http://dx.doi.org/ 10.1007/s00330-016-4293-7.

Steve Halligan

s.halligan@ucl.ac.uk; yangcan.gong@nhs.net

1 Centre for Medical Imaging, University College London,

London, UK

2 Public Health England, Fulwood House, Sheffield, UK

3 Department of Surgery and Cancer, Imperial College London, London, UK

4 Intestinal Imaging Centre, St Mark's Hospital, Harrow, UK 


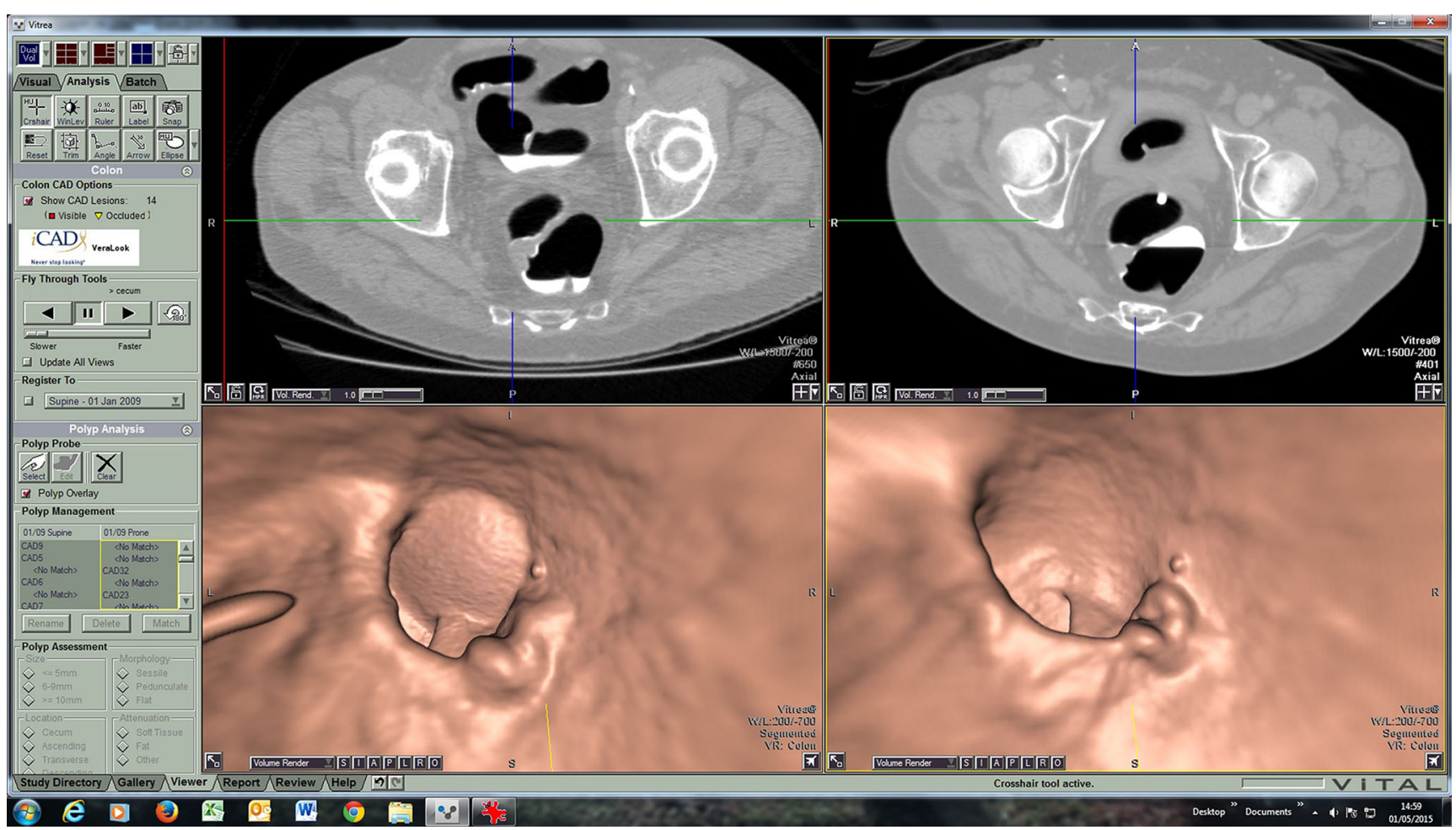

Fig. 3 Example of an upper rectal tumour missed by computer-aided detection (CAD) in a screening patient. Image quality was judged to be good by both readers, with a small amount of residual fluid which was well tagged 